shunt assembly and when appropriate had a reinsertion of his ventriculoperitoneal shunt. He remains well.

FRANCES LATCHAM
Hinchingbrooke Hospital,
Huntingdon,

1 Swann IL. Expulsion of ventriculoperitoneal shunt tubing. Arch Dis Child 1996; 74: 184.

EDITOR,-I was fascinated by Ian Swann's report of the patient passing per rectum the lower distal portion of a ventriculoperitoneal shunt. ${ }^{1}$ Although unreported, when I was a registrar in paediatric neurology at the Royal Hospital for Sick Children in Edinburgh, I was called by the nurses to see what they described as a worm having been passed into the nappy of a child with hydrocephalus. The young boy was completely asymptomatic, but on closer inspection we realised that this was a tube protruding from the baby's anus. Under gentle pressure the full length of the distal component of the shunt came away. At no time did he develop any further symptoms or signs unlike the reported patient. Although ventriculoperitoneal shunts not infrequently cause some local peritoneal inflammation or infection, such expulsion is obviously rare, but sadly not quite as unique as the case report implied.

O B EDEN

Christie Hospital NHS Trust, Wilmslow Road, Withington, Manchester M20 4BX

1 Swann II. Expulsion of ventriculoperitoneal shunt tubing. Arch Dis Child 1996; 74: 184.

\section{The effect of a child's disability on a mother's mental health}

EDrToR,-Have Dr Lambrenos and colleagues considered the possibility that the research process itself might have prevented some cases of depression? ${ }^{1}$ Firsly, before discharge from hospital the explanation given to the mothers of babies with abnormal ultrascans may have accelerated the grieving process involved in accepting a child with a disability, and prepared the mothers for cop- ing in the future. Secondly, the interviews by the research psychologist, although intended to be for assessment only, may have been therapeutic. A close, supportive relationship can develop between researchers and their subjects, and the unintended benefits to patients of involvement in a research trial have been noted before. ${ }^{2}$ It is possible that the opportunity to talk helped mothers cope with any feelings they had about their children's prematurity or potential disability, but did not alter the emotional consequences of psychosocial adversity. If this were the case, this apparently very well designed study could have inadvertently prevented the depressive disorder it was meant to detect.

QUENTIN SPENDER Department of General Psychiatry, Child and Adolescent Psychiatry Section, St George's Hospital Medical School, Cranmer Terrace, Tooting,

London SW17 ORE

\section{Dr Lambrenos comments:}

It is always possible, as Dr Spender points out, that the mothers in the study derived support from the research assessments. However, the research interview was wide ranging and did not focus on disability. Furthermore mothers of infants receiving the early physiotherapy intervention received much more professional support in addition to the research interviews. If talking about disability helped them to cope one would have expected to detect lower levels of depression in this group. These were not found. Up until the 12 month assessment only low levels of disability were evident. The mothers, rather than grieving, were relatively optimistic, and seemed to be denying the news broken to them on the neonatal intensive care unit. Perhaps grieving is a task to be negotiated by the mothers during the second year of their children's lives, when disabilities are evident.

1 Lambrenos $\mathrm{K}$, Weindling AM, Calam R, Cox $\mathrm{AD}$. The effect of a child's disability on mother's mental health. Arch Dis Child 1996; 74: er's mental

2 Reiser J, Wamer JO. The value of participating in an asthma trial. Lancet 1985; i: 206-7.
Thalidomide treatment of mucosal ulcerations in HIV infection

EDITOR,-The case report by Solèr and colleagues confirms the beneficial effects of thalidomide in treating aphthous ulcers in HIV/AIDS patients unresponsive to conventional treatments including oral prednisolone. ${ }^{1}$ One important side effect encountered in our centre and reported by others ${ }^{2}$ is irreversible peripheral neuropathy associated with prolonged high dose in patients with relapsing aphthous ulcers. Patients should be counselled about this as well as, of course, the teratogenic potential in females at risk of pregnancy.

TUBONYE C HARRY

Department of Genitourinary Medicine, Sunderland District General Hospital, Sunderland SR4 7TP

1 Solèr RA, Migliorati C, van Waes H, Nadal D. Thalidomide treatment of mucosal ulcerations in HIV infection. Arch Dis Child 1996; 74: 64-5.

2 Sophie D, Josette V, Bastuji-Garin S, Romain G, Jean $R$. Thalidomide neuropathy incidence and clinicoelectrophysiologic findings in 42 patients. Arch Dermatol 1994; 130: 66-9.

\section{Infant length measurements}

EDITOR,-Dr Falkner rightly commends the use of infant length measurements. ${ }^{1}$ But the available standards for length velocity must be treated with caution; some of these (including that quoted in Dr Falkner's letter) are derived from smoothed rather than observed data points and are thus liable to produce centiles which are too close together. ${ }^{2}$ The same caveat applies to some of the published standards for fetal growth velocities.

M J R HEALY 23 Coleridge Court, Milton Road, Harpenden AL5 SLD

1 Falkner F. Infant length measurements. Arch Dis Child 1995; 73: 379.

2 Royston P. Calculation of unconditional and conditional reference intervals for foetal size and growth from longitudinal measurements. Stat Med 1995; 14: 1417-36. 